\section{Internal Friction of Wires}

WORKING with the transverse vibrations of wires of glass, steel, brass, aluminium and silver, Bennewitz and Rötger ${ }^{1}$ have found that the internal friction has a maximum at a frequency $f_{0}$ characteristic of each wire. They have found, in fact, that the internal friction varies with frequency $f$ approximately as

$$
A \frac{f_{0} f}{f_{0}^{2}+f^{2}} .
$$

The purpose of this letter is to point out that the internal friction measured by Bennewitz and Rötger is a direct consequence of the entropy increase associated with the flow of heat from the compressed to the extended side of the wire. $f_{0}$ is interpreted as the reciprocal of the time of relaxation for the establishment of temperature equilibrium across the wire. The theory of this thermo-elastic internal friction has been discussed by $\mathrm{me}^{2}$ for the case of a reed. An extension of the theory to wires is being published elsewhere. It is found that $Q^{-1}$ for both reeds and wires (which is equal to the logarithmic decrement $\lambda$ of Bennewitz and Rötger multiplied by $\log _{e} 10 / \pi$ ) is given by (1), with

$$
A=\left(E_{S}-E_{T}\right) / E_{S},
$$

where $E_{S}$ and $E_{T}$ are the adiabatic and isothermal Young's moduli, respectively. In the case of wires, $f_{0}$ is given by

$$
f_{0}=\left(q^{2} / 2 \pi\right) D a^{-2}=0.539 D a^{-2},
$$

where $D$ is the thermal diffusion constant of the material, $a$ the radius of the wire, and $q$ the first root of the equation

namely, $1 \cdot 84$.

$$
(d / d x) J_{1}(x)=0
$$

Not only does the thermo-elastic effect give a satisfactory qualitative interpretation of the experiments of Bennewitz and Rötger, but also, as shown by the accompanying table, it gives good quantitative agreement.

\begin{tabular}{|l|l|l|l|l|l|}
\hline \multicolumn{1}{|c|}{ Type of wire } & Glass & Stecl & Brass & $\begin{array}{l}\text { Alum- } \\
\text { inium }\end{array}$ & Silver \\
\hline $2 a$ in mm. & $1 \cdot 25$ & $1 \cdot 0$ & $1 \cdot 25$ & $1 \cdot 5$ & $1 \cdot 01$ \\
$f_{0}$, observed & $0 \cdot 66$ & 25 & 40 & 83 & 240 \\
$0 \cdot 539 D a^{-2}$ & $0 \cdot 5-0 \cdot 6$ & 27 & 45 & 84 & 350 \\
$A \dagger \times 10^{3}$, observed & $8 \cdot 7$ & $2 \cdot 6$ & $4 \cdot 4$ & $5 \cdot 2$ & $6 \cdot 0$ \\
$\left(E_{S}-E_{T}\right)^{\prime} E_{S} \times 10^{3}$ & & $1 \cdot 9$ & $3 \cdot 2$ & $4 \cdot 6$ & $3 \cdot 7$ \\
\hline
\end{tabular}

$\dagger A$ has been obtained by multiplying $\lambda_{\max }$. of Bennewitz and Rötger by $2\left(\log _{e} 10\right) / \pi=1 \cdot 46$.

It is of particular interest to note that the fre. quency, $f_{0}$, at which the internal friction has a maximum is not a constant of the material, but varies inversely as the square of the radius of the wire.

Clareince Zener.

College of the City of New York,

New York.

${ }^{1}$ Bennewitz, K., and Rötger, H., Phys. Z., 37, 578 (1936).

${ }^{2}$ Zener, C., Phys. Rev., 52, 230 (1937).

\section{Capture of Slow Neutrons in Light Elements}

By means of a small boron-lined ionization chamber we have studied the density distribution of neutrons around a source ( $\mathrm{Ra}+\mathrm{Be}$ ) placed in a large container filled with a hydrogenous liquid ${ }^{1}$. From the measured distribution the total number of neutrons present at any instant is obtained by integration. This figure does not depend on the scattering properties but only on the capture cross-sections of the nuclei constituting the liquid. If a constant number of neutrons is emitted from the source, then the mean number present at any instant is inversely proportional to the total capture probability.

By using liquids containing the same constituents in different proportion we have been able to separate the capture effects due to the single constituents. First we compared benzene $\left(\mathrm{C}_{6} \mathrm{H}_{6}\right)$ and liquid paraffin $\left(\mathrm{CH}_{1 \cdot 87}\right.$, according to chemical analysis $)$. The numbers of neutrons in these two liquids were found to be inversely proportional to the respective hydrogen densities ; it follows that the capture cross-section of carbon must be much smaller than that of hydrogen. A similar result was found for oxygen, on comparing benzene and water. Through the kindness of a loan of 60 litres of heavy water of 10 per cent deuterium oxide content, from the Norsk Hydro-Elektrisk Kvælstofaktieselskab, Oslo, we were enabled to include deuterium in our experiments ; also in this case no measurable capture was detected. In a $7 \cdot 6$ per cent solution of ammonium nitrate in water, however, the capturing action of the nitrogen could be easily observed and measured.

We have also made measurements with aqueous solutions of boric acid and lithium hydroxide. Since the capture cross-sections of boron and lithium have been determined from experiments with beams of thermal neutrons, our measurements can be used to obtain absolute capture cross-sections for all the light elements quoted above. The results are collected below.

$$
\begin{array}{cccccc}
\multicolumn{5}{c}{\text { Capture cross-sections } \sigma_{c} \text { for neutrons of velocity }} & 2.2 \times 10^{5} \mathrm{~cm} . / \mathrm{sec} . \\
\text { Element } & \mathrm{H} & \mathrm{D} & \mathrm{C} & \mathrm{N} & 0 \\
\sigma_{\mathrm{c}} \times 10^{24} \mathrm{~cm}^{-2} & 0.27 \pm 0.02 & <0.03 & <0.01 & 1.3 . \pm 0.3 & <0.01
\end{array}
$$

Our value of $\sigma_{c}$ for hydrogen is somewhat smaller than the value given by Amaldi and Fermi $\left(0.31 \times 10^{-24} \mathrm{~cm}^{2}\right)$ which furthermore corresponds to a neutron velocity of $2.5 \times 10^{5} \mathrm{~cm}$. $/ \mathrm{sec}$. and should therefore be increased by a factor of $1 \cdot 13$ to be compared with our value. On the other liand, from neutron beam experiments we get a somewhat larger value ( 48 instead of $\left.43 \times 10^{-24} \mathrm{~cm}^{2}\right)^{1}$ for the scattering cross-section of hydrogen. For the mean number of collisions suffered by a slow neutron in paraffin before getting captured we find $205 \pm 20$ (instead of 140$)^{1}$.

Our value of $\sigma_{c}$ for nitrogen agrees with the value found $^{2}$ by counting the protons emitted in the reaction ${ }^{14} \mathrm{~N}+{ }^{1} n={ }^{14} \mathrm{C}+{ }^{1} \mathrm{H}$.

We may mention another result of our investigations. We have compared the yield of photo-neutrons from beryllium and deuterium irradiated by gamma rays from radium, with the vield from a mixture of radon and bervllium. Assuming the latter yield to be 20,000 neutrons per second per millicurie, we find for deuterium a cross-section of $\sigma_{2 \cdot 2}=7 \times 10^{-28} \mathrm{~cm} .^{2}$ for photo-dissociation by quanta of $2 \cdot 2 \mathrm{Mev}$. energy. For beryllium, where two gamma lines of $1.8 \mathrm{Mev}$. and $2 \cdot 2$ Mev. are sufficiently energetic, we find $\sigma_{1 \cdot 8}+0 \cdot 3 \sigma_{2 \cdot 2}=2 \times 10^{-27} \mathrm{~cm}^{2}$.

A detailed account is to appear shortly in the Proceedings of the Royal Academy, Copenhagen.

$$
\begin{aligned}
& \text { O. R. Frisch. } \\
& \text { H. voN HALBAN, JUN. } \\
& \text { JøRGEN Koch. }
\end{aligned}
$$

Institute for Theoretical Physics,

Copenhagen.

Oct. 20.

'Amaldi, E., and Fermi, E., Phys. Rev., 50, 899 (1936),

'Burcham, W. E., and Goldhaber, M., Proc. Camb. Phil. Soc., 32, $632(1936)$. 